\title{
JUSTICIA DE PAZ EN EL PERÚ
}

\section{Wilfredo Ardito Vega}

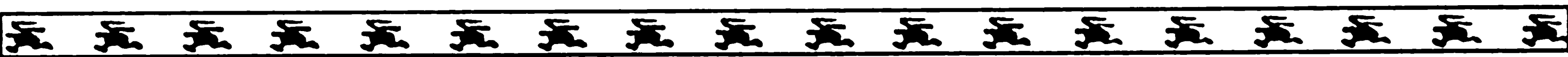

Durante los últimos años, las constituciones de Colombia, Perú, Bolivia, Ecuador y Venezuela han reconocido la facultad de administrar justicia a las autoridades de las comunidades indígenas. En el Perú, por razones históricas, este reconocimiento se expresa en relación a las autoridades de las comunidades campesinas y nativas $^{1}$. Sin embargo, en muchos casos, esta facultad no es ejercida por los líderes tradicionales de la población, sino por las personas que el Poder Judicial ha designado: los jueces de paz.

Existen en el Perú casi 5,000 jueces de paz, la mayoría ubicados en las zonas rurales, pero también ejerciendo en las principales ciudades $^{2}$. La ley les reconoce competencia para casos de deudas

${ }^{1}$ Las autoridades de las comunidades campesinas y nativas, con el apoyo de las rondas campesinas, pueden ejercer las funciones jurisdiccionales dentro de su ámbito territorial, de conformidad con el derecho consuetudinario, siempre que no violen los derechos fundamentales de la persona. La ley establece las formas de coordinación de dicha jurisdicción especial con los juzgados de paz y con las demás instancias del Poder Judicial (Artículo 149).

2 Se han encontrado jueces de paz en las zonas periféricas de Arequipa, Trujillo, Chiclayo e Ica. En Lima existen juzgados de paz en San Bartolo, Punta Negra, Pucusana, Pachacamac y Cieneguilla. 


\section{WILFREDO ARDITO VEGA}

hasta los 3,100 soles ${ }^{3}$, faltas, algunos trámites notariales y violencia familiar, pero en todos estos asuntos están autorizados por la Constitución y la Ley Orgánica del Poder Judicial para resolver de acuerdo a sus propios criterios de justicia.

Para los sectores más pobres de la población, suelen ser las únicas autoridades judiciales a las que pueden acudir y las que tienen mayor legitimidad social. Es muy frecuente además que los jueces de paz resuelvan casos que no son de su competencia, tanto por la presión de los litigantes como por lo costoso y distante de las demás instancias del Poder Judicial.

Esta realidad puede ser de difícil aceptación para quienes tienen una percepción positivista de la administración de justicia, pero también para quienes tienen una visión maniquea de las sociedades latinoamericanas, oponiendo Estado y población indígena, como dos mundos claramente diferenciados. Dentro de esta perspectiva, podría pensarse que los jueces de paz son parte de la expansión del Estado en el territorio nacional y que son empleados para violentar las culturas tradicionales en un proyecto homogeneizador. Pero la realidad es mucho más compleja (y cambiante) de lo que los propios campesinos y magistrados involucrados perciben.

\section{LA JUSTICIA DE PAZ EN EL PERÚ}

La justicia de paz peruana implica la existencia de magistrados que no son abogados, elegidos por su comunidad de acuerdo a sus méritos personales y participación en la vida comunal; esta es una realidad única en América Latina, lo que ha generado el interés de muchos juristas extranjeros ${ }^{4}$.

${ }^{3}$ Este cálculo depende de la Unidad Impositiva Tributaria (UIT) señalada cada año por el Estado. Sufre un incremento gradual de acuerdo a la inflación: el año 2000 era de 2,900 soles, el 2001 de 3,000. Aproximadamente son 880 dólares.

${ }^{4}$ Después de diversas visitas al Perú, se decidió implementar la justicia de paz en Venezuela, donde existen jueces de paz desde 1995 y en Colombia desde el año 2000. En ambos países el número de jueces de paz se calcula en unos 300 . La Constitución ecuatoriana también los contempla, pero hasta la fecha no se los ha llegado a instituir. 
Esta institución tiene sus primeros antecedentes en el espíritu democrático de la Constitución de las Cortes de Cádiz ${ }^{5}$, pero el Perú fue el único país independiente en que se mantuvo, como se aprecia desde la primera Constitución del año de $1823^{6}$.

Durante los primeros años de la República, no existía una clara distinción entre la función jurisdiccional y otros cargos públicos, por lo que el cargo de juez de paz era parte de las atribuciones de los alcaldes. Durante el siglo XIX, el juez de paz paulatinamente se convirtió en un vecino designado por el Poder Judicial, hasta que esto quedó definitivamente consagrado por la Ley Orgánica del Poder Judicial de 1911 ?.

Sin embargo, en la sociedad estamental peruana de comienzos del siglo XX, la función de juez de paz tenía un marcado carácter elitista. Sólo podía ocupar un cargo público quien era ciudadano, y sólo era ciudadano el vecino notable, es decir, un varón que supiera leer y escribir y tuviera propiedades. De esta manera, en las zonas rurales, el cargo de juez de paz era automáticamente ejercido por los únicos que cumplían estos requisitos: los hacendados o las personas de su entorno inmediato.

El poder que el hacendado tenía sobre los campesinos quedaba reforzado mediante las atribuciones judiciales que se le otorgaba sobre un determinado territorio. La jurisdicción del juez de paz hacendado podía, con frecuencia, ir más allá de su propiedad. El juez de paz tenía la facultad de aplicar "su leal saber y entender" al momento de resolver una controversia y el hacendado empleaba esta facultad para justificar los castigos corporales, el calabozo o la expulsión del indígena de la hacienda. En todo ello contaba con el apoyo de la fuerza pública, en los lugares donde existía, o de sus propios vigilantes. Para la población, y para el propio hacendado probablemente, era muy difícil distinguir entre el ejercicio de la función pública y la defensa de intereses privados.

5 "El alcalde de cada pueblo exercerá en él el oficio de conciliador, y el que tenga que demandar por negocios civiles o por injurias deberá presentarse a él con este objeto (artículo 282).

6 "No podrá entablarse demanda alguna civil sin haberse intentando la conciliación ante el Juez de Paz" (artículo 120). 1999, pp. 16-20.

${ }^{7}$ Un buen análisis de este proceso puede encontrarse en Lovatón et al., 


\section{WILFREDO ARDITO VEGA}

Con la reforma agraria y la desaparición de las haciendas, también los jueces de paz hacendados quedaron en el pasado, pasando el cargo a ser ejercido por una persona elegida por la propia comunidad. Actualmente, el juez de paz no suele ser una persona con poder económico o predominancia social. De igual forma, el cargo de juez de paz es ahora rotativo, pudiendo ser ejercido alternadamente por personas muy diversas de la comunidad o el poblado.

Sin embargo, los cambios poblacionales, como la migración y la urbanización, y otros fenómenos sociales, como la expansión del sistema educativo, han generado una marcada diferenciación entre los actuales jueces de paz en el Perú, la que debe ser precisada para evitar que se planteen tratamientos comunes a realidades heterogéneas.

Aproximadamente el $13 \%$ de los jueces de paz habita en la costa, en una realidad más urbana y donde la gran mayoría de la población está alfabetizada. Muchos jueces de paz son profesionales y un elevado porcentaje de ellos son abogados. En los casos en que se dedican a actividades manuales o a la agricultura, sí han planificado que sus hijos ingresen a la universidad. La mejor condición educativa y laboral de la mujer se refleja en el mayor porcentaje de mujeres que ejerce este cargo.

En la costa, muchos juzgados de paz son recientes, pues se establecieron ante la expansión demográfica y el surgimiento de nuevas zonas urbanas o semiurbanas, alrededor de las principales ciudades. La mayor densidad de habitantes lleva a que teóricamente exista un número elevado de usuarios por cada juez de paz, pero la ausencia de una pequeña comunidad de referencia, la incorporación a un medio laboral más formal y las facilidades para el transporte hacen menos importante la función del juez de paz en este entorno social. Muchas personas prefieren acudir a un juzgado de paz letrado o a un notario, porque sienten que les da más garantía. En los casos en que acuden al juez de paz, pueden también hacerse presentes con su abogado, con el que puede entablarse una relación conflictiva ${ }^{8}$.

${ }^{8}$ Muchos jueces de paz de la costa señalan como un serio problema la interferencia de abogados, quienes los menosprecian por no haber estudiado derecho y pretenden obligarlos a resolver de manera formal. 
Es altamente posible que el Poder Judicial formal pueda extenderse y consolidarse en la costa a través del nombramiento de juzgados de paz letrados y que se vaya expandiendo el notariado formal, dada la mayor actividad económica en la región.

En la región andina es donde reside la gran mayoría de los jueces de paz (73.6\%), aunque actualmente no es la región más poblada del país. Esto se debe a que muchos juzgados de paz tienen origen histórico, es decir, fueron establecidos cuando la mayor parte de la población peruana estaba concentrada en la sierra. A pesar de la migración a la costa y la selva, los juzgados de paz se han mantenido en buena medida porque continúan las condiciones de aislamiento de la población rural y para ésta sería materialmente imposible acudir a un juzgado de paz letrado.

En la región andina, la justicia de paz opera en pequeñas comunidades, en las cuales los vecinos se conocen mutuamente y tienen una serie de relaciones múltiples: familiares, laborales, religiosas, educativas, etcétera. Por ello, para los integrantes de la comunidad es muy importante mantener la armonía al interior del grupo y lograr resolver los conflictos de forma eficaz. Los involucrados saben que continuarán viviendo juntos por mucho tiempo y que una solución de los conflictos no debe generar resentimientos o problemas mayores, como sucede con las sentencias de otras instancias del Poder Judicial.

El juez de paz andino es conocido y respetado por los ciudadanos y basa el cumplimiento de sus decisiones no tanto en la ley sino en su capacidad de persuasión y su autoridad moral. Éstas son características subjetivas que sólo pueden ser importantes en un círculo relativamente pequeño.

La mayoría de los jueces de paz en la sierra son agricultores y no tienen estudios superiores, por lo cual no existe mayor distancia respecto a las partes. Es más, con frecuencia puede presumirse que posteriormente uno de los litigantes puede ser elegido como sucesor del juez de paz. Un factor de mayor cercanía aún es que el juez de paz habla el idioma de las partes: castellano en Cajamarca, quechua en Huancavelica, aimara en el sur de Puno y jacaru en Tupe (Yauyos). Además, cuando las partes se comunican en castellano, el juez de paz emplea un lenguaje cercano, sin tecnicismos legales ni frases rebuscadas. 


\section{WILFREDO ARDITO VEGA}

Sin embargo, a pesar de su legitimidad, los jueces de paz no gozan del apoyo que la Ley Orgánica del Poder Judicial establece, disponiendo que las comunidades o municipios les proporcionen un despacho y mobiliario. Normalmente, esto no se cumple y atienden en su propio domicilio, teniendo muchas carencias de infraestructura.

Desde el punto de vista étnico, podría señalarse que la mayor parte de los jueces de paz andinos tiene un origen indígena, lo cual es bastante lógico, dado que se trata de una región que normalmente no recibe migrantes. Sin embargo, para la población, éste no parece ser un factor determinante. Como se verá más adelante, son criterios importantes de selección el nivel educativo y la participación en la vida comunal y no tanto los rasgos físicos de la persona ni su lugar de procedencia.

El tema de la identidad es una de las diferencias marcadas con respecto a los jueces de paz amazónicos: debido a la colonización relativamente reciente, la selva es la región peruana donde la población tiene conciencia más clara de su identidad étnica. Tanto el $10 \%$ de población nativa como el $90 \%$ de colonos tienen mucha conciencia de serlo y suelen mirar con desconfianza al otro componente social.

Los juzgados de paz en la Amazonía suelen tener su sede en la capital distrital, pero los distritos amazónicos son sumamente extensos ${ }^{9}$. En la capital suelen concentrarse los mestizos o colonos entre los cuales se elige a las autoridades del distrito. Por lo tanto, la gran mayoría de jueces de paz son mestizos que sólo hablan castellano, desconocen las prácticas culturales de la población nativa y en ocasiones ni siquiera ocultan su desprecio hacia ella.

Como resultado, estos jueces de paz son una autoridad lejana para la población nativa. Los nativos prefieren no acudir al juez de paz mestizo, porque sienten que no va a comprender sus problemas (en muchos casos ni siquiera hay comprensión lingüística). Ellos sostienen que si tienen un conflicto con un mestizo, el juez de paz siempre favorecerá a éste último, por sus vínculos económicos y afinidad étnica. Existen acusaciones de que algunos jueces de paz mestizos pertenecen al grupo de los "patrones" y establecen con la

${ }^{9}$ Algunos tan extensos como el departamento de Apurímac. 


\section{JUSTICIA DE PAZ EN EL PERÚ}

población nativa una relación similar a los jueces de paz hacendados del siglo pasado para mantener su poder.

Ante este panorama, los grupos nativos más organizados han decidido plantear al Poder-Judicial la posibilidad de que algunas comunidades nativas más pobladas o estratégicamente ubicadas también sean sedes de juzgados de paz. De esta manera, actualmente existen jueces de paz aguarunas, shipibos, lamistas y asháninkas, quienes administran justicia en el idioma de la población. Ellos asumen conscientemente que su función incluye promover los intereses del grupo nativo, incluyendo la identidad y la cultura. Los jueces de paz nativos se basan en el derecho consuetudinario para tomar decisiones y eso es lo que se espera de ellos ${ }^{10}$.

El número de jueces de paz nativos es todavía reducido, pero esto no se debe tanto al desinterés de la población sino a la resistencia del Poder Judicial a incrementar el número de juzgados de paz en la Amazonía ${ }^{11}$.

\section{ElECCIONES Y CAMBIOS CULTURALES}

En 1999, la ahora desactivada Comisión Ejecutiva del Poder Judicial $^{12}$ dispuso en dos sucesivas resoluciones administrativas ${ }^{13}$ la generalización de los procesos de elección popular de jueces de paz. Hasta ese año, sólo las comunidades campesinas y nativas elegían a sus jueces de paz mediante asambleas, mientras que en distritos y caseríos eran designados por el Poder Judicial a partir de

${ }^{10}$ En algunos distritos existen un juez de paz nativo y uno colono, con lo cual parece regresarse a la división étnica de la administración de justicia que existía en la Colonia entre indios y españoles.

${ }_{11}$ Mientras en los distritos judiciales de Loreto y Ucayali los jueces de paz no pasan de 40, en los distritos judiciales de Cajamarca o Ancash son más de 400. Aun distritos judiciales relativamente pequeños, como Apurímac y Huancavelica, tienen tres o cuatro veces más jueces de paz que los distritos judiciales de la zona amazónica.

12 Se trataba de una instancia de control del Poder Judicial establecida por el Gobierno de Alberto Fujimori que permitía garantizar los intereses políticos y económicos del régimen, pero no llegó a interferir activamente con la justicia de paz, por cuanto no era una instancia tan importante políticamente.

13 Resoluciones administrativas 844 y 1062. 


\section{WILFREDO ARDITO VEGA}

las propuestas de las autoridades locales. Las mencionadas resoluciones no se conformaban a lo dispuesto por la Constitución de $1993^{14}$, pero tuvieron como resultado que efectivamente se realizaran procesos de elección de jueces de paz en todo el Perú. Un estudio realizado por el Instituto de Defensa Legal después de las elecciones revela una serie de cambios culturales que se daban en la población y que fueron alterando el perfil de los jueces de paz, comparando los resultados con una investigación similar realizada en 1998.

En los datos que se presentan a continuación se aprecian las diferencias que hemos señalado entre diversas regiones del Perú.

\section{Disminución de la edad de los jueces de paz}

Los resultados demuestran que, especialmente en la costa, existe la tendencia a pasar del juez de paz tradicional, una persona mayor que decide los casos de acuerdo a su experiencia, a elegir jueces de paz más jóvenes, pero que pueden comprender mejor las nuevas situaciones o dar un enfoque diferente a antiguos problemas.

Edad de los jueces de paz por región

\begin{tabular}{|l|c|c|c|c|}
\hline & $\begin{array}{c}\text { Menores de } \\
35 \text { años }\end{array}$ & De 35 a 50 años & De 50 a 65 años & $\begin{array}{c}\text { Más de } \\
65 \text { años }\end{array}$ \\
\hline Costa & $25.5 \%$ & $53.7 \%$ & $18.4 \%$ & $2.2 \%$ \\
Sierra & $17 \%$ & $48.2 \%$ & $27.5 \%$ & $7.1 \%$ \\
Selva & $22.6 \%$ & $52 \%$ & $22.5 \%$ & $2.8 \%$ \\
\hline
\end{tabular}

${ }^{14}$ La Constitución establece que una ley debe regular la elección de los jueces de paz. 


\section{JUSTICIA DE PAZ EN EL PERÚ}

La edad promedio de los jueces de paz ha disminuido. En 1998, un tercio de ellos tenía más de 50 años. Actualmente sólo se puede encontrar un porcentaje similar en la región andina.

Porcentaje de jueces de paz mayores de 50 años

\begin{tabular}{|l|l|l|}
\hline & 1998 & 2000 \\
\hline Costa & $30 \%$ & $20.6 \%$ \\
Sierra & $36.6 \%$ & $34.6 \%$ \\
Selva & $28 \%$ & $25.3 \%$ \\
\hline
\end{tabular}

De esta manera tenemos que, precisamente en las zonas de la costa, donde la esperanza de vida es más alta, la población prefiere elegir jueces de paz más jóvenes. Los jueces de paz mayores suelen tener menor instrucción, especialmente en las zonas andinas, donde la mayoría sólo ha estudiado primaria. Por lo tanto, eligiendo a una persona más joven, se puede garantizar que tenga mayor nivel educativo, siendo, como veremos a continuación, otro criterio importante la formación profesional.

\section{Incremento del número de jueces de paz mujeres}

Las resoluciones administrativas del año 1999 establecieron una serie de normas para fomentar la presencia de mujeres en el cargo de jueces de paz que no tenían carácter determinante, pero podían incidir en ello ${ }^{15}$.

La norma tuvo como resultado que muchas mujeres se incorporaran al cargo, especialmente en aquellos lugares más

15 Establecían que el $40 \%$ de los candidatos debían ser mujeres y que obligatoriamente una mujer debía estar entre los elegidos (el juez de paz y sus dos accesitarios). Estos requisitos fueron cuestionados por implicar una violación de los derechos de los electores. Se criticó también que en las zonas rurales el analfabetismo femenino puede convertir esta norma en impracticable. 


\section{WILFREDO ARDITO VEGA}

cercanos a las zonas rurales. En la zona andina, el porcentaje de mujeres llega actualmente al $11.6 \%$, mientras que en la Amazonía llega al $13 \%$. Inclusive, en los distritos judiciales más tradicionales, como Ayacucho o Huancavelica, donde en 1998 la totalidad de los jueces eran varones, ahora tenemos un porcentaje del $10 \%$ de mujeres. Tomando en cuenta la proporción de jueces de paz existente en cada región, podemos decir que, en la actualidad, el $14 \%$ son mujeres.

Paulatinamente, la población rural está aceptando una autoridad femenina, especialmente los jóvenes y las mismas mujeres. Sin embargo, personas mayores en la zona andina se han mostrado muy escépticos respecto al desempeño de una mujer como juez de paz. En la zona de Puno, muchas mujeres han indicado que las presiones de sus maridos les han impedido aceptar el cargo

Las visitas a las comunidades en las zonas rurales demuestran también que algunas mujeres asumen nominalmente el cargo de juez de paz, pero que en la práctica éste es ejercido por un varón: el padre, el esposo o el secretario. Esto sucede especialmente si éstos han tenido mayor experiencia como jueces de paz o han estado vinculados al aparato judicial ${ }^{16}$. Sin embargo, muchas mujeres están ejerciendo el cargo de manera independiente, especialmente cuando han tenido alguna experiencia personal importante (maestras, dirigentes comunales, comerciantes).

En muchos lugares, un factor clave para la elección de una mujer es el mayor nivel educativo: el $41.2 \%$ de las mujeres encuestadas tiene educación superior completa, frente a menos del $20 \%$ de los varones. Del mismo modo, el $14.7 \%$ de las mujeres encuestadas son abogadas, frente a menos del $4 \%$ en el caso de los varones. Para un alto porcentaje de ellas (27.5\%), éste es su primer cargo público, frente al $17.4 \%$ de los varones.

En general, una vez que la mujer asume el cargo, suelen ser consideradas personas muy honestas. Se indica también que son

${ }^{16}$ En otros casos, la mujer había sido elegida en segundo lugar, pero la Corte Superior decidió que asumiera el cargo. Esto generó el natural rechazo de la población, que considera como su juez de paz legítimo al que ellos eligieron como tal. 
más sensibles frente a la violencia familiar y los casos de alimentos. Finalmente, no se tienen noticias de casos de alcoholismo, como sí ha habido denuncias respecto a los jueces de paz varones.

\section{Aumento del nivel educativo}

Se aprecia que la población tiende a elegir como jueces de paz a personas que han estudiado y tienen una mayor formación desde el punto de vista occidental. El juez de paz tradicional, es decir, la persona cuya sabiduría derivaba de su edad, está coexistiendo con jueces de paz más jóvenes e instruidos. Estos cambios revelan también cambios en la comunidad.

\begin{tabular}{|l|l|l|l|l|l|}
\hline & Primaria & $\begin{array}{c}\text { Secundaria } \\
\text { incompleta }\end{array}$ & $\begin{array}{c}\text { Secundaria } \\
\text { completa }\end{array}$ & $\begin{array}{c}\text { Superior } \\
\text { incompleta }\end{array}$ & Superior \\
\hline Costa & $3.4 \%$ & $5.5 \%$ & $25.3 \%$ & $15.1 \%$ & $50.7 \%$ \\
Sierra & $22.7 \%$ & $19.4 \%$ & $27.3 \%$ & $9.3 \%$ & $20.6 \%$ \\
Selva & $27.8 \%$ & $13.9 \%$ & $33.8 \%$ & $13.2 \%$ & $10.6 \%$ \\
\hline
\end{tabular}

En la costa, la justicia de paz parecería paulatinamente quedar en manos de personas con formación profesional: $65.8 \%$ en el año 2000 frente a $57.2 \%$ en 1998.

De igual manera, tenemos que en estas nuevas elecciones ha disminuido el porcentaje de jueces de paz en la sierra que sólo habían estudiado primaria: de $29.4 \%$ en 1998 a $22.7 \%$ en la actualidad.

Muchas veces los cambios son más visibles en las mujeres: ellas tienen un nivel educativo muy superior al promedio de los jueces de paz varones. Esto revela que cuando una persona tiene una educación superior, la población está dispuesta a confiar en ella. De igual forma, cuando se elige a una persona que lleva poco tiempo en la comunidad, ésta generalmente tiene instrucción superior y ha residido mucho tiempo en una ciudad grande. 
Finalmente, en la costa un $41.4 \%$ de los jueces de paz ha seguido la carrera de derecho y un $26.7 \%$ son abogados. Se aprecia así que, en una región más urbanizada, la población tiene más interés por una solución técnica a sus problemas que por los mecanismos tradicionales de persuasión.

\section{Mejor manejo de las normas}

Diversas actividades de capacitación, generalmente a cargo de organismos no gubernamentales, han generado en los jueces de paz un mejor conocimiento de la legislación peruana, lo cual ha sido especialmente importante en materias relacionadas con los derechos de la mujer, como casos de alimentos, violencia familiar y violencia sexual.

Igualmente, un creciente número de jueces de paz ha asumido como parte de sus funciones la posibilidad de sentenciar, lo cual rompe el estereotipo tradicional del juez conciliador. Más allá de la voluntad de las partes, el juez puede plantear sus propios criterios de justicia para resolver un conflicto.

Este conocimiento se aprecia muchas veces en las actas de conciliación, en las cuales el juez de paz aplica las normas que sancionan a los agresores. De igual forma, se aprecia que no sólo se conoce mejor la normatividad, sino que se comprende mejor la problemática.

En el ámbito de la violencia familiar, los jueces de paz que han asistido a sesiones de capacitación suelen buscar otras alternativas diferentes a la conciliación. Su práctica no se basa en pedir a la víctima que perdone a su esposo, sino en buscar evitar que se reanude la violencia. Estos jueces de paz llegan a disponer que el agresor abandone el hogar conyugal o inclusive que sea detenido, siguiendo las disposiciones de la Ley de Protección contra la Violencia Familiar. Cabe señalar que hemos encontrado estas actitudes inclusive en jueces de paz que pertenecen a una población nativa amazónica, pero que han recibido una capacitación especial en la materia. En muchos otros lugares, la norma es citada con frecuencia por el juez de paz.

De la misma manera, encontramos que aparece en las actas de conciliación una cláusula por la cual se sanciona al agresor con 
JUSTICIA DE PAZ EN EL PERÚ

diversas penalidades en caso de reincidencia. Las sanciones van desde una multa en favor de la comunidad o de la víctima hasta la detención o la denuncia a la autoridad superior. Es importante el contraste respecto a las actas más tradicionales, en las cuales se reflejaba la voluntad del juez de obligar a la víctima a perdonar al agresor, e inclusive se indicaban las obligaciones que debía cumplir ("obediencia", "cumplir los deberes domésticos") para no ser maltratada. Estas actas eran frecuentes en la zona andina hasta hace unos años, pero actualmente los jueces de paz tienen un enfoque más crítico respecto a las posibilidades de conciliar casos de violencia familiar.

\section{COORDINACIÓN, COEXISTENCIA O CONFLICTO}

La coexistencia de la justicia de paz con otras autoridades comunales podría llevar a una serie de conflictos de competencia. Teóricamente, dos litigantes podrían acudir a instancias diferentes, eligiendo la que pueda favorecerlos más. Sin embargo, hemos encontrado que generalmente existen acuerdos tácitos para distinguir cuáles materias son apreciadas por el juez de paz o por las autoridades comunales. Estos acuerdos dependen muchas veces de las relaciones personales que se establezcan al interior de la comunidad $^{17}$.

La capacitación en derechos humanos, especialmente en derechos de la mujer y del niño, puede ser un factor que genere una nueva división en cuanto a la competencia. Las alternativas que a continuación se presentan están pensadas básicamente para un contexto andino, donde existe una organización comunal definida y sólida, una marcada importancia de la justicia de paz para resolver conflictos, una población relativamente homogénea y la mayoría de jueces de paz son personas de la zona.

17 Un factor adicional puede ser la influencia política del partido de Gobierno. Tanto en los gobiernos de Fujimori como de Toledo, hubo gobernadores $y$ tenientes gobernadores que pretendieron asumir funciones judiciales, generándose conflictos con los jueces de paz. 


\section{Coexistencia de ambas instancias}

En estos casos, las autoridades tradicionales resuelven los conflictos que no han sido previstos por las normas estatales: los padrinos del matrimonio sancionan un caso de adulterio y las autoridades comunales intervienen frente al incumplimiento de las tareas comunales. El juez de paz, en cambio, resuelve aquellos asuntos de su competencia legal como alimentos o deudas y atiende trámites notariales. Otra división de competencia es que los mecanismos tradicionales concentran su labor en problemas entre habitantes de la comunidad, mientras que las personas que vienen de fuera prefieren acudir al juez de paz. Sin embargo, es bastante frecuente que el juez exceda sus atribuciones legales debido a la insistencia de las partes, por lo que no se podría afirmar que el juez de paz se limita simplemente a cumplir la ley.

Son frecuentes los mecanismos de colaboración: las autoridades comunales pueden remitir al juez de paz algunos casos que consideran complejos o acuden también a las audiencias de conciliación. En éstas también están presentes los padrinos de matrimonio ${ }^{18}$ cuando se trata de un problema conyugal. Pueden también comprometerse a realizar el seguimiento de los acuerdos a que lleguen las partes o las sentencias del juez. Cuando éste dispone una sanción legal, como la prestación de servicios comunitarios, suele cumplirse de acuerdo a lo dispuesto por las autoridades comunales. Lo mismo puede ocurrir cuando se impone una sanción que la ley no contempla, como cuando se indica que, en caso de reincidencia en violencia familiar, los padrinos aplicarán una "sanción drástica", lo cual probablemente hace referencia a castigos corporales.

La justicia de paz también suele convertirse en un mecanismo para que determinadas prácticas y valores comunales puedan imponerse a una persona que reside temporalmente en la comunidad.

18 Por ejemplo, en un acta sobre violencia familiar en un juzgado de paz de Huancavelica se advierte que la conciliación no podía realizarse porque no estaban presentes los padrinos. 


\section{JUSTICIA DE PAZ EN EL PERÚ}

\section{Juez de paz como órgano jurisdiccional de la comunidad con criterios culturales propios}

Cada vez es más frecuente que las autoridades comunales prefieran asumir la tarea productiva y la representación de la comunidad ante las autoridades estatales, delegando la resolución de conflictos al juez de paz. Esto sucede especialmente cuando la comunidad está más desarrollada, hasta convertirse en distrito, y en la población también aparecen autoridades rentadas por el Gobierno (alcaldes, regidores, gobernadores). El juez de paz asume en estos casos también los problemas que la comunidad percibe como tales y que la ley no ha previsto. Son conocidas las denuncias por brujería o adulterio o los intentos de los padres de familia por forzar o impedir el matrimonio de sus hijos, especialmente de las mujeres. El juez, en estos casos, toma su decisión de acuerdo con los valores comunales y es claramente un representante de éstos ${ }^{19}$.

Sin embargo, también en aspectos que son de su competencia el juez de paz sigue los patrones culturales tradicionales. Los criterios entre problemas públicos y privados son distintos de aquellos manejados por el Poder Judicial, al punto de que delitos como la violación o una agresión seria pueden ser conciliados.

De esta forma, en muchos lugares del Perú, el juez de paz centraliza tanto las facultades que la ley le indica como la resolución de conflictos tradicionales. A esto se asuman casos que son competencia de otras instancias judiciales, a las cuales, debido a la distancia, la población no puede acudir.

\section{Jueces de paz con actitudes legalistas}

Existe también un grupo minoritario de jueces de paz que pretende resolver los conflictos ante su despacho de manera sumamente legalista. Esto puede pasar porque el juez tiene algún tipo de formación jurídica, porque siente cierto desdén por las tradiciones

19 Entre los jueces de paz nativos es explícito este respeto a las prácticas culturales propias, siempre que no impliquen serias violaciones a los derechos humanos. 


\section{WILFREDO ARDITO VEGA}

comunales o porque en los cursos de capacitación ha sido amenazado por los magistrados de la Corte Superior con ser sancionado por prevaricato si no se restringe a su competencia o decide de manera distinta a lo que señala la ley.

En estos casos, el juez de paz se muestra mucho más rígido que un magistrado formal, pues normalmente desconoce la diferencia entre dolo y culpa, los límites de la legítima defensa, el error culturalmente condicionado o los derechos de la víctima. Estos jueces asumen, además, que no pueden sentenciar $y$, cuando no consiguen una conciliación efectiva, prefieren abstenerse de tomar una decisión y remiten el caso a una instancia superior.

De esta manera, la población pierde el control sobre situaciones que podrían ser resueltas localmente y muchas veces, dada la inaccesibilidad de las autoridades estatales, el problema no se soluciona $^{20}$.

\section{Subordinación del juez de paz}

En algunos lugares de Cajamarca, la ronda campesina surgió precisamente para enfrentar la figura del juez de paz, corrupto y vinculado con los poderes locales. En esas zonas, hasta la fecha, el juez de paz es un cargo que se mantiene de forma nominal y está subordinado a la autoridad de la ronda campesina. Lo más frecuente, sin embargo, es que se respeten ambos espacios: el juez de paz mantiene sus funciones notariales e interviene en algunos problemas de carácter legal, como los linderos. De igual forma, otorga una formalidad legal a las decisiones de las rondas campesinas, mientras que éstas ayudan al cumplimiento de sus decisiones. Normalmente, un dirigente rondero es elegido también como juez de paz y cumple ambas funciones sin mayor problema.

La subordinación del juez de paz tiene consecuencias más peligrosas en aquellos lugares de Cusco y Ayacucho donde existen

${ }^{20}$ En la Amazonía, este desenlace puede ser intencional: si un nativo ha cometido un delito muy grave, los demás integrantes de la comunidad pueden asumir que no existe la posibilidad de rehabilitarlo y que la convivencia con él es imposible. La cárcel o el simple traslado a la ciudad cumple la función de proteger a la comunidad de la persona irrecuperable. 
comités de autodefensa, que son un remanente de la lucha antisubversiva. Estos comités toman decisiones arbitrarias, contrarias a los derechos fundamentales y a la justicia $y$, sin embargo, el juez de paz las acata por temor a una reacción violenta del comité.

Cabe señalar que se trata de zonas donde el sistema de haciendas generó una marcada tradición autoritaria, posteriormente reforzada durante los años de la violencia. Se trata de una administración de justicia basada en el castigo y no en la conciliación o el consenso. Existen pocas perspectivas de que esta situación cambie, debido a que ni los organismos no gubernamentales ni el Poder Judicial realizan actividades de capacitación con los comités de autodefensa. Inclusive, en una Corte Superior se nos manifestó que brindarles capacitación implicaba reconocer una labor de administración de justicia que legal y constitucionalmente no tenían.

\section{JUSTICIA DE PAZ Y PODER JUDICIAL}

Los jueces de paz tienen una doble legitimidad: además de ser elegidos por sus vecinos, son designados oficialmente y deben prestar juramento ante la Corte Superior. El Poder Judicial está obligado a entregarles útiles de escritorio y a capacitarlos, aunque esto sucede con poca frecuencia. Sin embargo, no existe una actitud homogénea dentro del Poder Judicial hacia los jueces de paz y más bien hemos podido apreciar diversas tendencias que, en ocasiones, coexisten dentro del mismo distrito judicial. El cambio de presidente de la Corte Superior puede implicar también actitudes más favorables o indiferentes hacia los jueces de paz.

\section{Tendencia legalista}

Se trata de una tendencia que nace del positivismo que impregna la formación legal en casi todas las universidades peruanas. Se identifica justicia con derecho y derecho con ley, generando que el magistrado considere que su función es aplicar la ley y que analizar los efectos que pueda tener ésta en una realidad pluricultural es un elemento que no le corresponde. Se parte de que el derecho estatal es el único que existe en el Perú. Es una visión etnocéntrica de la 


\section{WILFREDO ARDITO VEGA}

sociedad, coloca al sector autodenominado occidental como modelo. Si existen diferencias culturales, éstas son las que deben ser superadas.

Naturalmente, esta percepción etnocéntrica tiene un fuerte componente de racismo: los magistrados de la costa tienen muchas dificultades para comprender la realidad andina. Sin embargo, también tenemos "autorracismo", porque, curiosamente, en algunas cortes superiores de la región andina predomina esta mentalidad, a pesar de que los mismos magistrados tengan rasgos indígenas. Es mucho más visible la necesidad de diferenciarse del campesino y, en este caso, la educación se convierte en nuevo factor discriminatorio.

Por todo ello, se manifiesta un fuerte rechazo hacia todos los mecanismos propios de la población. El artículo 149 de la Constitución no es conocido o es interpretado de manera sumamente restringida: en algunos casos se sostiene que las comunidades sólo pueden atender problemas de menor cuantía, es decir, que su competencia es equivalente a la de los jueces de paz, aunque la Constitución no realiza esta distinción ${ }^{21}$.

No es una postura que se base en el respeto por los derechos humanos. De hecho, los magistrados que forman parte de esta tendencia pueden pasar por alto muchas violaciones a estos derechos cometidas por policías contra campesinos. Tampoco se basan en realidad en el Estado de derecho o la legalidad, pues muchas veces se trata de magistrados y fiscales que aplicaron sin mayores problemas morales las normas inconstitucionales del régimen de Fujimori.

Para estos funcionarios, la justicia de paz es un fenómeno temporal, de transición, un mal necesario debido a las dificultades de los demás niveles de la administración de justicia para llegar a las zonas rurales. Mientras deba existir la justicia de paz, sería deseable que se otorgue el cargo exclusivamente a abogados o egresados de derecho; por ello la elección popular parece una alternativa errónea ${ }^{22}$.

${ }^{21}$ Debe aclararse, sin embargo, que la población nativa y campesina sí practica normalmente esta distinción, entregando a las autoridades judiciales a los responsables de delitos graves, como los homicidios. artículo 69.

22 La Ley Orgánica del Poder Judicial expresa esta preferencia en el 
Cuando eventualmente se organiza un curso de capacitación para los jueces de paz campesinos, estos magistrados procuran "formalizarlos" entregándoles códigos y normas, dictando charlas que explican los procedimientos legales y mostrando siempre la amenaza de incurrir en prevaricato. Se intenta, por lo tanto, descontaminar al juez de paz de las influencias culturales locales.

Naturalmente, por realizarse en un lenguaje técnico y sin una metodología didáctica, las capacitaciones no llegan a ser comprendidas por los jueces de paz. Lo que sí captan es un fuerte temor a que alguna persona interponga su queja ante la Oficina Distrital de Control de la Magistratura (ODICMA) y se sancione al juez de paz simplemente por ignorar algún requisito formal o resolver de acuerdo a su criterio de justicia. Ante este temor, algunos prefieren derivar la mayoría de casos a otros niveles del Poder Judicial, con lo cual la justicia de paz no cumple la función de descongestionar el sistema.

\section{Tendencia relativista}

Para esta tendencia, el Convenio 169 sobre pueblos indígenas de la Organización Internacional del Trabajo y el artículo 149 de la Constitución implican que el Poder Judicial se abstenga de intervenir en todos aquellos problemas que afecten a campesinos o nativos, aunque sean ellos mismos quienes soliciten la intervención. La justicia de paz es considerada la forma en que el Poder Judicial tiene presencia en esta población, siendo preferible que las demás instancias de la administración de justicia no se involucren.

La ausencia de intervención en la justicia de paz genera una serie de ventajas al Poder Judicial y el Ministerio Público: en primer lugar, es una reducción de la carga procesal. Igualmente, para muchos magistrados y fiscales, atender una demanda o denuncia proveniente de una comunidad implicaría viajar a lugares sumamente distantes para poder resolverla, y ellos saben que, en la práctica, muy pocos campesinos podrán llegar a impulsar el proceso. A esto añadimos las dificultades lingüísticas, que harían a estos juicios muy complicados. 


\section{WILFREDO ARDITO VEGA}

Para los integrantes de esta tendencia, las violaciones a los derechos humanos son tradiciones que no pueden ser erradicadas $y$ consideran que se trata de "su justicia", con la que es preferible no enfrentarse. El juez de paz debería limitarse a actuar según los valores comunitarios, sin criticarlos ni oponerse, evitando conflictos inútiles. No debería intervenir ni siquiera en un caso de castigo físico o un linchamiento, si se trata de prácticas con aceptación de la comunidad $^{23}$.

Nosotros creemos que el problema de fondo es que los derechos $e$ intereses de la población rural tienen menos prioridad para estas autoridades y la referencia a los derechos humanos en el artículo 149 no es tomada en cuenta, porque los derechos humanos provienen de la cultura occidental. Algunos magistrados sostienen, por ejemplo, que la violación no existe en las comunidades campesinas, es decir, que se produce, pero que las víctimas se resignan por razones culturales o simplemente se casan, sin generar la controversia que se produce en las zonas urbanas.

En el fondo, otorgar una valoración absoluta al derecho consuetudinario es más bien una forma de evitar intervenir en casos complicados, en los cuales los derechos e intereses en juego son de grupos sociales discriminados. Asumiéndose que se trata de sus propias normas, se termina considerando a los campesinos como peruanos de segunda categoría, para los cuales no funcionan las normas de protección de derechos fundamentales que sí se aplican a los demás peruanos.

\section{Tendencia comunitaria}

Esta tendencia busca reconciliar el respeto por la autonomía de la población campesina y nativa con el respeto por los derechos humanos. Este es un camino difícil, en el que existen numerosos conflictos, porque cada caso concreto debe ser analizado con atención.

${ }^{23}$ En una corte superior se destituyó a un juez de paz por haber denunciado un caso de azotes a una mujer, argumentando que él no debía ponerse en contra del derecho consuetudinario. 


\section{JUSTICIA DE PAZ EN EL PERÚ}

Para estos magistrados, la justicia de paz es vista como un valor en sí misma porque, frente a las distorsiones y malos usos de la justicia estatal, consigue llegar con mayor certeza a los ideales que ésta teóricamente pretende.

Ellos parten de una posición mucho más crítica sobre el propio Poder Judicial y consideran que las decisiones que se toman en la población pueden ser más rápidas, más comprensibles y más adecuadas a la realidad. Por ello promueven que los jueces de paz actúen según criterios de equidad y consideren los valores comunales, antes que cumplir rigurosamente la ley. Estos magistrados consideran que la opción de colocar abogados como jueces de paz puede generar una distorsión del cargo, ya que estaría basándose más bien en criterios legales ajenos a la realidad de la población.

Con respecto a las violaciones de los derechos humanos que pueda cometer la población, estos magistrados los consideran casos aislados, que deben ser manejados de manera individual, para apreciar si es aplicable el criterio del error culturalmente condicionado que recoge el artículo 15 del Código Penal y que se refiere a cuando la persona comete un hecho delictivo sin poder comprenderlo, debido a su cultura o a sus costumbres.

Lo fundamental es prevenir estos hechos mediante la incorporación a la cultura local del respeto por los derechos humanos. Se busca crear sensibilidad en los comuneros sobre aspectos como el derecho a la integridad física y los derechos de la mujer, de la misma forma que debería fomentarse entre los actores de la administración de justicia y las fuerzas policiales.

En los últimos años, el Poder Judicial ha aceptado la realización de actividades de capacitación, por diversos organismos no gubernamentales, de jueces de paz y autoridades comunales, con lo cual se ha generado una tendencia distinta en la toma de decisiones y resolución de conflictos. Han surgido criterios nuevos que se basan en la situación de la víctima, la problemática de violencia familiar y una interpretación finalista de la justicia.

Tenemos jueces de paz que adoptan criterios distintos, tanto de la mentalidad tradicional como de la mentalidad legalista. Por ejemplo, cuando no se impone una reconciliación a una víctima de violencia familiar, sino se procura asegurar la protección de la vícti- 


\section{WILFREDO ARDITO VEGA}

ma. Es posible que en algunos casos exista un conflicto entre los valores que el juez de paz desea preservar y aquellos que la comunidad mantiene. El conflicto puede manifestarse, por ejemplo, si se pretende aplicar castigos corporales a un adúltero o un ladrón. Se han producido experiencias difíciles para algunos jueces de paz, pero han conseguido que se logren evitar linchamientos o que se produzcan otros hechos violentos.

Sin embargo, en las comunidades mismas se están produciendo fenómenos nuevos, especialmente en cuanto a una mayor autonomía de la mujer y una búsqueda de reafirmación de sus derechos. Es posible que la integridad física, como un valor, esté siendo aprendida actualmente por muchas personas dentro de la población andina, siendo un concepto que no existía hace unos años.

La educación, la urbanización y la migración pueden estar modificanda también las decisiones de las autoridades comunales. Especialmente en las rondas campesinas se ha advertido una tendencia más visible a dejar de lado sanciones corporales y priorizar otras formas de solución de conflictos. Por esto, actualmente ya no es tan posible como antaño pretender acusar a los ronderos por el delito de lesiones. Los jueces de paz pueden ser también parte de ese proceso, cumpliendo una función educativa en sus comunidades. Sin embargo, son solamente una influencia junto con las otras que ya existen en este sentido.

En todo caso, la tendencia comunitaria puede tener una posibilidad de trabajo conjunto con este sector creciente de jueces de paz.

\section{CONCLUSIONES}

La existencia de la justicia de paz demuestra las complejas relaciones existentes entre la población rural y el aparato estatal. A lo largo de las últimas décadas, estas relaciones han sufrido diferentes cambios, según el grado de presencia del Estado, pero también según las características propias de la población.

Desde nuestro punto de vista, los habitantes de las comunidades generalmente son conscientes de la posibilidad de acudir a instancias diversas, según la naturaleza del problema. Para la po- 
blación andina, el juez de paz tiene un carácter de bisagra, en él confluyen la racionalidad de las normas y los problemas propios de la población.

Existen jueces de paz más inmersos en la cultura local, que se asumen como integrantes de su comunidad y consideran su legitimidad social como un elemento fundamental. La población espera de ellos el respeto a sus costumbres y tradiciones. Es posible que esto se manifieste también en sociedades que han incorporado formas muy recientes de administración de justicia, como las rondas campesinas.

El otro extremo es la minoría de jueces de paz que han estudiado derecho o se consideran más preparados que el común de la población. Ellos asumen que parte de su labor de administrar justicia consiste en corregir las prácticas tradicionales de la comunidad para ayudar al progreso de todos. Por ello, están interesados en conocer las normas y procedimientos legales, aunque no tengan real utilidad para los casos concretos.

La mayoría de los jueces de paz se encuentra en una situación intermedia, queriendo cumplir el espíritu de las normas, pero también ser fieles a sus valores. Sin embargo, nuestra tesis es que los valores comunales están también en permanente cambio. Creemos que es en la población rural del Perú donde los cambios culturales se manifiestan con mayor rapidez y profundidad. Las prácticas y costumbres relacionadas con una sociedad tradicional y autoritaria pueden ir diluyéndose, sin que esto necesariamente signifique que los jueces de paz se conviertan en funcionarios legalistas.

A la larga, es posible que sean estos nuevos jueces de paz, más modernos y comprometidos, quienes con más eficacia cumplan los valores que el Estado oficialmente busca promover. 


\section{Bibliografía}

ARDITO, Wilfredo

1994 “Son los derechos humanos un concepto universal?", en Desfaçiendo Entuertos, № 3-4, Lima.

1996 Los indígenas en las leyes de América Latina, Survival International, Londres.

1997 "The Right to Self-Regulation: Legal Pluralism and Human Rights in Peru", en Journal of Legal Pluralism and Unofficial Law, 39, Glasgow.

1998 "Racismo, novedades sobre un viejo problema", en Ideele, 108, Lima.

ARdito, Wilfredo; Heise, María y Tubino, Fidel

1995 Interculturalidad, un desafío, CAAAP, $2^{\mathrm{a}}$ ed., Lima.

BRANDT, Hans-Jürgen

1987 Justicia popular: nativos y campesinos, Centro de Investigaciones Judiciales de la Corte Suprema de la República y Fundación Friedrich Naumann, Lima.

1990 En nombre de la paz comunal. Un análisis de la justicia de paz en el Perú, Centro de Investigaciones Judiciales de la Corte Suprema de la República y Fundación Friedrich Naumann, Lima. 


\section{JUSTICIA DE PAZ EN EL PERÚ}

\section{De TRAZEGNIES, Fernando}

1993 Postmodernidad y pluralismo jurídico, Universidad Nacional San Agustín, Arequipa.

De tRAZEgnies, Fernando; Revilla, Ana Teresa y Urteaga, Patricia 1992 "Pluralismo jurídico, posibilidades, necesidades y límites", en Máximo Gallo (Edt.), Comunidades campesinas y nativas en el nuevo contexto nacional, CAAAP y SER, Lima.

Gálvez, Modesto

1987 "El derecho en el campesinado andino en el Perú", en Diego García Sayán (Edt.), Derechos humanos en el campo, CAJ y CIJ, pp. 233-244, Lima.

Lovatón, David; Ardito, Wilfredo; Montoya, Yván y Márquez, Jaime 1999 Justicia de paz: el otro Poder Judicial, IDL, Lima.

PÁsara, Luis

1982 Jueces, justicia y poder en el Perú, CEDYS, Lima.

PeÑa JUMPA, Antonio

1998 Justicia comunal en los Andes del Perú: el caso de Calahuyo, PUCP, Lima; "Justicia comunal en Calahuyo", en Allpanchis $\mathrm{N}^{\circ}$ 37, Instituto de Pastoral Andina, Cusco.

Revilla, Ana Teresa y Price, Jorge

1991 La administración de la justicia informal. Posibilidades de integración, Ed. Cultural Cuzco, Lima.

TAMAYo, Ana María

1992 Derecho en los Andes. Un estudio de antropología jurídica, CEPAR.

Urteaga, Patricia

1993 El sistema jurídico y su relación con la cultura nativa. El caso de las comunidades aguarunas, Lima, PUCP (tesis para optar el grado de abogada). 


\section{WILFREDO ARDITO VEGA}

1994 "Recuperando la justicia. El caso de una comunidad aguaruna", en Desfaçiendo Entuertos, № 2, Lima.

YRIGOYEn, Raquel

1993 Las rondas campesinas de Cajamarca. Una aproximación desde la antropología jurídica, PUCP (tesis para optar el grado de abogada).

1993 "Apuntes sobre el artículo 149 de la Constitución peruana: alcances, límites, consecuencias y retos, en Desfaçiendo Entuertos, № 2, Lima. 